\title{
Protective Effect of Lyophilization on Fermentative, Microbiological and Sensory Properties of Kefir
}

\author{
Ana F Moretti ${ }^{1}$, Raúl Ricardo Gamba ${ }^{4}$, Maria do Céu Costa ${ }^{2}$, Graciela De Antoni ${ }^{1-3}$ and Ángela María León Peláez ${ }^{4 \star}$ \\ ${ }^{1}$ Centro de Investigación y Desarrollo en Criotecnología de Alimentos (CIDCA- CCT CONICET). Facultad de Ciencias Exactas, \\ Universidad Nacional de La Plata, La Plata, Argentina \\ ${ }^{2}$ ECTS/CBIOS - The Biosciences Research Center and NICiTeS/ERISA - Núcleo de Investigação em Ciências e Tecnologias da Saúde, \\ Grupo Lusófona, Lisboa, Portugal \\ ${ }^{3}$ Comisión de Investigaciones Científicas de la Provincia de Buenos Aires (CIC-PBA), Buenos Aires, Argentina \\ ${ }^{4}$ Cátedra de Microbiología, Facultad de Ciencias Exactas, Universidad Nacional de La Plata, La Plata, Argentina
}

\section{Article Info}

\section{*Corresponding author: \\ Ángela María León Peláez \\ Professor \\ Facultad de Ciencias Exactas \\ Universidad Nacional de La Plata \\ Argentina \\ E-mail: anleon@biol.unlp.edu.ar}

Received: March 27, 2019

Accepted: July 10, 2019

Published: July 19, 2019

Citation: Moretti AF, Gamba RR, Costa M, De Antoni G, Peláez ÁL. Protective Effect of Lyophilization on Fermentative, Microbiological and Sensory Properties of Kefir. Int J Biochem Pharmacol. 2019; 1(1): 5-11.

doi: 10.18689/ijbp-1000102

Copyright: (c) 2019 The Author(s). This work is licensed under a Creative Commons Attribution 4.0 International License, which permits unrestricted use, distribution, and reproduction in any medium, provided the original work is properly cited.

Published by Madridge Publishers

\begin{abstract}
Kefir is a fermented beverage produced from kefir starter, by means of the milk fermentation with kefir grains. These grains are a protein and polysaccharide matrix that contains Lactic Acid Bacteria (LAB), Acetic Acid Bacteria (BAA) and yeasts. This study aimed to assess the protective activity of the lyophilization process on the activity of kefir grains by comparing their microbiological composition, sensory characteristics and antimicrobial effect on fermented products obtained either from lyophilized and fresh kefir grains. Acidification kinetics and microbial counts were performed on fermented milks obtained from fresh or freeze-dried grains. Inhibitory activity tests against Escherichia coli and Salmonella enterica serovar Enteritidis were carried out with different dilutions of cell free supernatants from fermented milks. On the other hand, similarity and acceptability tests were performed to compare the sensory characteristics of fermented milks obtained from fresh and freeze-dried grains. The microbiological composition and acidification capability of the freeze-dried grains were stable until 6 months of storage at $4^{\circ} \mathrm{C}$. Moreover, the minimum inhibitory concentration of fresh and freeze-dried grains was similar ( $20 \% \mathrm{v} / \mathrm{v})$ for both pathogens. Additionally, the sensory panel did not detect differences between milk fermented with fresh or freeze-dried kefir grains; the kefir beverage obtained from the freeze-dried kefir grains fermentation showed a wide sensory acceptance among the population surveyed. We considered that lyophilization followed by the storage conditions applied were suitable for the survival of the kefir micro biota, the sensory characteristics and the antimicrobial capability of the fermented beverage after an adequate reactivation process of the grains. In conclusion, the reactivation process risk management is an important stage to ensure a suitable carriage and therefore maximize the kefir grains for large scale use.
\end{abstract}

Keywords: Lyophilization; Kefir; Antimicrobial activity; Escherichia coli; Salmonella enterica serovar Enteritidis; Sensory evaluation.

\section{Introduction}

Kefir is fermented milk traditionally produced from kefir grains. It is obtained by fermentation of milk with kefir grains which are composed of diverse Lactic acid bacteria $(\mathrm{LAB})$ and yeasts incorporated in a polysaccharide and protein matrix [1]. A symbiotic relationship exists between the bacteria and the yeasts [2] and their combined growth results in a fermented product with distinct flavor characteristics and effervescence. This fermented product is claimed to act against pathogens like Salmonella, Shigella, Bacillus 
cereus, Staphylococcus, E. coli and fungi [3-8]. Nevertheless, there are difficulties to transport high amounts of fresh grains due to the need of large volumes of milk and the loss of activity during long times of transport of the wet grains. Also, fermentation process continues during transportation triggering changes of organoleptic properties of kefir, which is undesirable.

A pioneering work has been reported by Brially [9] on preservation of the intrinsic inhibitory power of dairy kefir after lyophilization by testing several desiccation substrates and several regeneration media. The tested cryoprotectors were ribitol, sodium glutamate and glycerol. After lyophilization, the pellets of kefir were regenerated in water or milk. Glycerol was the best cryoprotector because of its high efficiency and its low cost, white sodium glutamate was unsatisfactory. Other group conducted afterwards a study on the various kefir preservation techniques as freezing, refrigeration, air-drying and lyophilization at $-18,4$ and $24^{\circ} \mathrm{C}$ of storage temperatures, showing that the acidification activity of the kefir grains continued for 10 months [10]. However, the kefir micro biota was not determined. More recently, Tugba Kok Tas [11] showed that the conservation of kefir grains by lyophilization process protects the embedded micro biota during 2 months of storage at $4^{\circ} \mathrm{C}$. Nevertheless, neither the chemical composition or the sensory analysis nor the inhibitory power of the fermented product with freezedried kefir grains was investigated.

The aim of the present study was to assess the protective activity of the lyophilization process on the activity of the CIDCA AGK1 kefir grains by comparing its microbiological composition, chemical and sensory characteristics and its antimicrobial effect with those corresponding to the fermented products obtained either from lyophilized and fresh kefir grains.

\section{Materials and methods}

\section{Kefir grains, bacterial strains and growth conditions}

CIDCA AGK1 kefir grains were characterized previously and stored at $-20^{\circ} \mathrm{C}$ at CIDCA (Centro de Investigación y Desarrollo en Criotecnología de Alimentos- FCE- UNLP) [12]. The kefir grains were reactivated and kept by subcultures in UHT whole milk (Sancor ${ }^{\circledR}$, Santa Fe, Argentina). For the assays, the kefir grains were inoculated at a concentration of $10 \%\left(\mathrm{w} / \mathrm{v}\right.$ ) in UHT whole milk (Sancor ${ }^{\circledR}$ ) at $30^{\circ} \mathrm{C}$.

Salmonella enteric serovar Enteritidis and Escherichia coli ATCC 25922 were used as test microorganisms, which were activated in nutrient broth by incubation at $37^{\circ} \mathrm{C}$ for $24 \mathrm{~h}$. A $0.5 \mathrm{McFarland}$ suspension of each pathogen was prepared (corresponding to $10^{8} \mathrm{CFU} \cdot \mathrm{mL}^{-1}$ ). The counts of viable bacteria and yeasts in fermented products were determined by plating serial dilutions in tryptone $\left(1 \mathrm{~g} \cdot \mathrm{L}^{-1}\right)$ on Plate Count Agar (Merck, Darmstadt, Germany) agar plates. S. entérica serovar Enteritidis and E. coli ATCC 25922 were obtained from Instituto Biológico Doctor Tomás Perón (La Plata, Argentina). Both strains were kept by successive passages in sterile nutrient agar (Parafarm, Buenos Aires, Argentina) slant.

\section{Kefir grains lyophilization and storage conditions}

Kefir grains were suspended in UHT whole milk, used as a cryoprotectant agent, and were frozen, first to $-20^{\circ} \mathrm{C}$ and then to $-80^{\circ} \mathrm{C}$. The frozen samples were lyophilized overnight under vacuum at $1 \mathrm{~Pa}$ (temperature condition: $-39^{\circ} \mathrm{C}$ ), using a Rificor L-A-B3 freeze- dryer ${ }^{\circledR}$ (Rificor, Buenos Aires, Argentina). Freeze-dried kefir grains were stored for 6 months at $4^{\circ} \mathrm{C}$. Kefir beverages were produced from these freezedried kefir grains at 0, 1,3 and 6 months of storage. Previously, the freeze-dried kefir grains were reactivated by two consecutive passages in UHT whole milk $(10 \% \mathrm{w} / \mathrm{v})$ at $30^{\circ} \mathrm{C}$. This previous step was made for all determinations, unless otherwise noted.

\section{Microbial counts}

Serial dilutions from kefir beverages or kefir grains were prepared in sterile tryptone $\left(1 \mathrm{~g} \cdot \mathrm{L}^{-1}\right)$ (Britania, Buenos Aires, Argentina). Previously, kefir grains were disrupted in a mortar and suspended in sterile tryptone $\left(1 \mathrm{~g} . \mathrm{L}^{-1}\right)$. Viable bacteria and yeast concentrations were determined by plating appropriate dilutions on agar plates as previously described [13]. Lactic Acid Bacteria (LAB) counts were performed on De Man, Rogosa, and Sharpe agar medium (Difco, Beauvais, France) and yeasts were grown on Yeast Glucose Chloramphenicol agar medium (Biokar Diagnostics, Beauvais, France). All plates were incubated at $30^{\circ} \mathrm{C}$ for 48 hours in an aerobic atmosphere. Viable counts were performed in duplicate. Results were expressed as colony forming units per milliliter (CFU. $\mathrm{mL}^{-1}$ ) of fermented milk or colony forming units per gram of wet kefir grains $\left(\mathrm{CFU} . \mathrm{g}^{-1}\right)$, as appropriate [1].

Both freeze-dried and fresh kefir grains had two different activation processes. The microbial counts of the freeze-dried kefir grains were conducted by activating freeze-dried grains by two successive passages in milk or by taking the kefir grains directly from the vial. The microbial counts of fresh kefir grains were made directly from frozen kefir grains or from grains that were active by two successive passages in milk.

\section{Acidification kinetics}

Acidification kinetics of fermented milk with fresh and freeze-dried kefir grains was studied at 0, 1, 3 and 6 months of storage $\left(4^{\circ} \mathrm{C}\right)$. Kefir grains were inoculated in UHT whole milk $(10 \% \mathrm{w} / \mathrm{v})$ and the fermentation was conducted at $30^{\circ} \mathrm{C}$. Samples were taken at regular time intervals during fermentation and $\mathrm{pH}$ was measured with an ALTRONIX TPXIIITM (Altronix, Taiwan) instrument, until the value was constant.

\section{Determination of wet weight of kefir grains}

CIDCA AGK1 kefir grains were sub cultured by successive passages in a suitable volume of milk $(10 \% \mathrm{w} / \mathrm{v})$ and incubated at $30^{\circ} \mathrm{C}$ for 24 hours. Kefir grains were washed with sterile water, dried between tissue paper, and weighed on a PRECISA XB 220 analytical balance (Dietikon, Switzerland) [13]. Biomass was expressed as Relative Variation of biomass, which is the rate between the final and the initial grain weight. 


\section{Physicochemical analysis}

The physicochemical composition of fermented milk with freeze-dried grains was studied at time 0, 1, 3 and 6 months of storage. Protein content was determined by Kjeldahl method and acidity by $\mathrm{NaOH} 0.1$ mol. $\mathrm{L}^{-1}$ titration. The protein content was calculated by multiplying the total nitrogen by 6.38 [14].

\section{Antibacterial activity of cell free supernatants (CFS)}

The inhibitory activity of cell free supernatants (CFS) from fermented milk with fresh and reactivated freeze-dried kefir grains, stored at $4^{\circ} \mathrm{C}$ for 6 months, against $E$. coli y $S$. enteric serovar Enteritidis was tested. The minimal inhibitory concentration (MIC) and the quantitative inhibitory activity were determined.

Inhibitory activity test: CFS were obtained by centrifugation at $13,000 \mathrm{~g}$ for $15 \mathrm{~min}$ and filtered through $0.20 \mu \mathrm{m}$ cellulose acetate membrane (Sartorius, Madrid, Spain). The CFS was diluted in nutrient broth to reach concentrations of $20 \%, 30 \%$, $40 \%, 50 \%$ and $60 \% \mathrm{v} / \mathrm{v}$. A volume of $1 \mathrm{~mL}$ of each dilution was inoculated with $10 \mu \mathrm{L}$ of pathogen suspension, uniformly mixed and incubated at $37^{\circ} \mathrm{C}$ for 48 hours. Pathogen growth was detected by turbidity. The Minimum Inhibitory Concentration (MIC) was considered as the lowest percent concentration of CFS assayed that completely inhibited the visible bacterial growth. Aliquots of suspensions without turbidity were sub cultured in nutrient agar (Parafarm) and incubated at $37^{\circ} \mathrm{C}$ for $24 \mathrm{~h}$. The Minimum Bactericidal Concentration (MBC) was considered as the lowest percent concentration of CFS that prevented bacterial growth [7]. The results were used to determine the effect of CFS on the growth of these pathogens.

Effect of CFS on E. coli ATCC 25922 and S. enteric serovar Enteritidis growth: A volume of $1 \mathrm{~mL}$ of sterile nutrient broth with CFS was prepared according to the MIC values obtained. The solution was inoculated with $100 \mu \mathrm{L}$ of microorganism (0.5 McFarland suspensions), uniformly mixed and incubated at $37^{\circ} \mathrm{C}$. Counts of viable bacteria at different incubation times $(1,4,7,10$ and 24 hours) in sterile nutrient agar (Parafarm). Each treatment was performed in duplicate.

\section{Sensory analysis}

The sensory panel was composed of people who regularly consumed dairy products like yoghurt and kefir. In order to detect differences between samples it is considered as enough the selection of individuals with good discriminatory power and bearing experience acquired over time of consumption [15].

To study the effect of the lyophilization and the storage time on the sensory characteristics of kefir, two different techniques were performed [16,17]. All sensory assays were carried out in a tasting room designed to fulfill the requirements stipulated by the International Standards [18], consisting of an area for the preparation of the samples along with seven separate isolation cabinets for the panelists with controlled humidity and luminosity. During the evaluation, each panelist was situated in an individual booth under incandescent light of intensity approximately $350 \mathrm{~lx}$.

The samples were kefir obtained with freeze-dried kefir grains after 6 months of storage at $4^{\circ} \mathrm{C}$ and kefir fermented with fresh kefir grains. A volume of $50 \mathrm{ml}$ of each sample was served in transparent plastic cups at $10^{\circ} \mathrm{C}$. Tap water was provided between samples to rinse the palate. The samples were coded by three-digit numbers and given to the panelists in aleatory fashion. The order of sample evaluation was randomized for each panelist and was presented in such a manner that the panelist could not identify the sample.

Similarity test: Two successive triangle tests placed on a tray were given to each panelist. Each tray consisted of 3 samples: 2 identical and 1 different samples (two samples obtained with freeze-dried grains and one sample obtained with fresh grains or one sample from freeze-dried grains and two samples from fresh grains).

A number of 27 panelists were asked to taste the samples in the order indicated on their ballot sheets [19], and to identify the different sample. The values obtained were analyzed using the following equation.

$L S \%=\left[(1.5 x(x / n)-0.5)+1.5 \times Z_{\beta} x V\left(\left(n \cdot x-x^{2}\right) / n^{3}\right)\right] \times 100$, Equation 1, where $L S \%=u p p e r$ limit of the panelist's percentage; $\mathrm{x}=$ number of correct answers; $\mathrm{n}=$ number of panelists; $Z_{\beta}=1.64$ (value corresponding to one tail of the normal curve), $\beta=5 \%$. Statistical parameters for similarity were $\alpha=0.10 ; \beta=0.05$ with an estimated proportion of discriminators (Pd) of 30\% [20].

Acceptability test: This test was made in order to assess the acceptability of the kefir obtained with freeze-dried kefir grains stored for 6 months at $4^{\circ} \mathrm{C}$. This test was carried out in a public place into the Universidad Nacional de La Plata. Randomly, people who passed by the place was asked to taste the sample and to qualify the product in a 9-point hedonic scale. A total of 93 untrained panelists qualified the product with a score between 1 ("dislike very much") to 9 ("I like very much") [21].

\section{Statistical analysis}

The results obtained for microbial counts, physicochemical analysis and the acidification kinetics during milk fermentation were expressed as means \pm SD of at least three independent triplicate trials. For statistical comparisons, ANOVA and Fisher's test at a 0.05 level of significance were performed.

\section{Results}

\section{Biomass increase of fresh and freeze-dried kefir grains during milk fermentation process}

Both fresh and freeze-dried kefir grains increased their biomass at the end of the assay after 23 days. Fresh kefir grains increased their biomass 1.77 times compared to their initial biomass, whereas freeze-dried kefir grains increased their biomass 1.32 times compared to their initial biomass (Figure 1). 


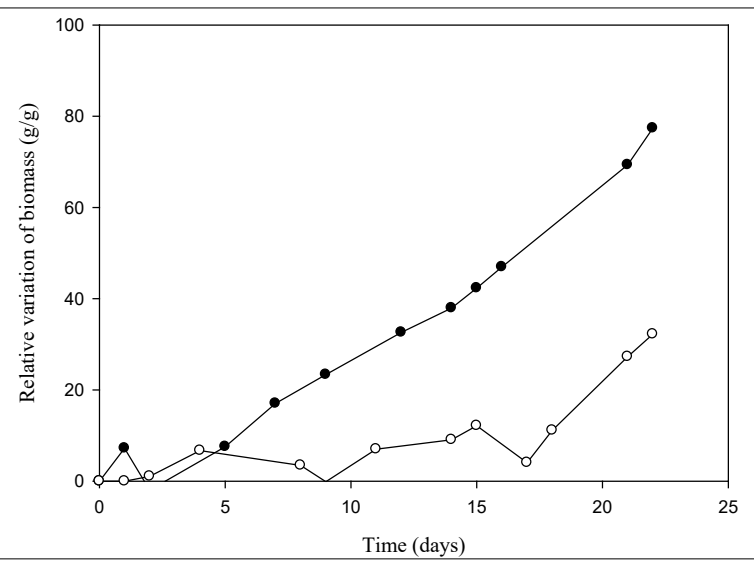

Figure 1. Biomass increase of reactivated freeze-dried CIDCA AGK1 kefir grains stored for 6 months at $4^{\circ} \mathrm{C}(O)$ and fresh CIDCA AGK1 kefir grains $(\bullet)$. The assay was performed during 23 days.

\section{Microbial counts of fresh and freeze-dried kefir grains and fermented milks obtained from them}

Microbial counts of freeze-dried and fresh kefir grains were conducted in two ways to assess whether the lyophilization affects the microorganisms' survival in the grains with or without a reactivation step. Table 1 shows that no-significant difference was observed between the plate counts for Lactic Acid Bacteria (LAB) and yeasts of fresh and freeze-dried kefir grains with reactivation step (stored for 6 months). However, freeze-dried kefir grains without reactivation presented a significant decrease of three and four logarithmic orders in $L A B$ and yeasts, respectively. Therefore, the reactivation step is essential to achieve equal microorganism concentration, both in freeze-dried and fresh kefir grains (Table 1).

Table 1. Microbiological composition of freeze-dried kefir grains stored for 6 months at $4^{\circ} \mathrm{C}$.

\begin{tabular}{|l|c|c|}
\hline Treatment & LAB (CFU.g $\left.{ }^{-1}\right)$ & Yeasts $\left(\right.$ CFU. g $\left.^{-1}\right)$ \\
\hline Fresh kefir grains & $6.14 \pm 0.56 \times 10^{8}$ & $0.94 \pm 0.41 \times 10^{8}$ \\
\hline $\begin{array}{l}\text { Freeze-dried kefir grains, } 6 \text { months of } \\
\text { storage, without reactivation }\end{array}$ & $3.30 \pm 0.62 \times 10^{5^{*}}$ & $1.97 \pm 1.28 \times 10^{4^{*}}$ \\
\hline $\begin{array}{l}\text { Freeze-dried kefir grains, } 6 \text { months of } \\
\text { storage, reactivated }\end{array}$ & $2.88 \pm 0.70 \times 10^{8}$ & $1.25 \pm 0.17 \times 10^{8}$ \\
\hline
\end{tabular}

Results obtained for microbial counts were expressed as means \pm SD of at least three independent triplicate trials. Different stars indicate significant differences $(p<.05)$, analyzed by ANOVA, followed by Fisher's test.

Table 2. Characteristics of the fermented milk obtained from freeze-dried kefir grains at different storage time at $4^{\circ} \mathrm{C}$. Fermented milk was always prepared with reactivated freeze-dried kefir grains.

\begin{tabular}{|c|c|c|c|c|}
\hline \multirow{2}{*}{ Treatment } & \multirow{2}{*}{$\begin{array}{l}\text { Acidification } \\
\text { slope } \\
\text { ( } 0 \text { to } 7 \mathrm{~h} \text { ) }\end{array}$} & \multirow{2}{*}{\begin{tabular}{|c|} 
Time \\
required \\
to reach \\
$\mathrm{pH} 4(\mathrm{~h})$
\end{tabular}} & \multicolumn{2}{|c|}{$\begin{array}{c}\text { Microbial counts of the kefir } \\
\text { beverage }\end{array}$} \\
\hline & & & $\begin{array}{l}\text { LAB } \\
\left(C F U \cdot g^{-1}\right)\end{array}$ & $\begin{array}{c}\text { Yeasts } \\
\text { (CFU.g-1) }\end{array}$ \\
\hline Fresh (Control) & & 8 & $0.81 \pm 0.01 \times 10^{8^{*}}$ & $2.27 \pm 0.65 \times 10^{6^{*}}$ \\
\hline Freeze-dried, zerc & -0.13 & 22 & $2.07 \pm 0.21 \times 10^{8^{*, *+*}}$ & $4.64 \pm 0.38 \times 10^{6, *+,+,}$ \\
\hline Freeze-dried, 1 month & -0.16 & 13 & $2.36 \pm 1.06 \times 10^{0^{8+x+4+0}}$ & $2.34 \pm 0.66 \times 10^{6+*}$ \\
\hline Freeze-dried, 3 months & -0.24 & 18 & $3.12 \pm 0.56 \times 10^{8^{*+x+x}}$ & $2.29 \pm 0.84 \times 10^{7 \times+x+k}$ \\
\hline Freeze-dried, 6 months & -0.21 & 17 & $2.64 \pm 0.20 \times 10^{8+k+x}$ & $1.26 \pm 0.47 \times 10^{7 \times+x}$ \\
\hline
\end{tabular}

Results obtained for microbial counts were expressed as means \pm SD of at least three independent triplicate trials. Different stars indicate significant differences $(p<.05)$, analyzed by ANOVA, followed by Fisher's test.

The LAB counts of milk fermented with fresh and reactivated freeze-dried kefir grains showed significant difference. Moreover, the freeze-dried grains $L A B$ counts were one order higher than those obtained with the fresh grains. A similar result was obtained with the yeast counts. The freeze-dried grains yeasts counts were one order higher than those obtained with the fresh grains at the 3 and 6 months of storage (Table 2).

\section{Acidification kinetics during milk fermentation with fresh and freeze-dried kefir grains}

Results showed that freeze-dried kefir grains kept the acidification ability without showing a significant difference between the treatments and the fresh grains (Table 2).

Figure 2 shows that all treatments produced a $\mathrm{pH}$ decrease when the kefir grains were inoculated in milk. The acidification kinetics for all treatments was pronounced during the first hours approximately between 3 and 7 hours. Once the first 15 hours was passed, the acidification rate decreased until it reached a plateau. The acidification kinetics between fresh and freeze-dried grains did not show significant differences.

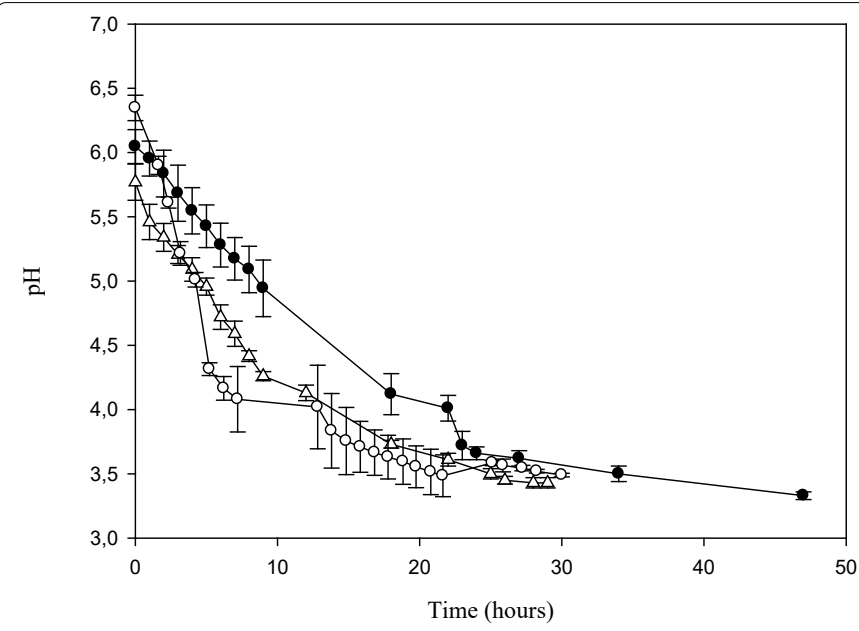

Figure 2. Acidification kinetics of milk fermented with CIDCA AGK1 kefir grains. Fresh $(O)$ and freeze -dried kefir grains at storage time $0(\bullet)$ and storage time 6 months $(\rho)$. Kefir grains were reactivated by two successive passages in UHT milk. The acidification kinetics assays were carried out under the following conditions: $10 \% \mathrm{w} / \mathrm{v}$ of CIDCA AGK1 kefir grains in commercial UHT milk at $30^{\circ} \mathrm{C}$.

\section{Physicochemical analysis of the fermented milk with freeze- dried kefir grains}

Protein concentration of fermented milk with freeze-dried grains showed no statistically significant differences between all the values during the storage (Table 3 ). The titratable acidity did not show statistically significant differences between values obtained at 0 and 1 month, but if at 3 and 6 months of storage. The titratable acidity (except months 0 and 1) and protein concentration values were within the limits required by the national legislation [22].

Table 3. Physicochemical analysis of fermented milk with freezedried kefir grains. Protein concentration and Titratable acidity at 0 , 1, 3 and 6 months of storage.

\begin{tabular}{|l|c|c|}
\hline $\begin{array}{l}\text { Storage time } \\
\text { (months) }\end{array}$ & $\begin{array}{c}\text { Protein concentration } \\
\left(\mathrm{g} .100 . \mathrm{g}^{-1}\right)\end{array}$ & $\begin{array}{c}\text { Titratable acidity } \\
\left.\text { (lactic acid g.100. } \mathrm{g}^{-1}\right)\end{array}$ \\
\hline 0 & $3.35 \pm 0.07$ & 0.43 \\
\hline 1 & $3.60 \pm 0.23$ & 0.49 \\
\hline 3 & $3.95 \pm 0.09$ & 0.85 \\
\hline 6 & $3.56 \pm 0.09$ & 0.74 \\
\hline
\end{tabular}




\section{Antibacterial activity of fermented milk with fresh and freeze-dried kefir grains}

Inhibitory activity test: Inhibitory activity of CFS obtained from the fermentation of freeze-dried (with reactivation in milk) and fresh kefir grains at different concentrations (20\% to $60 \%$ CFS) were tested. All the CFS concentrations tested (from fresh and reactivated freeze-dried kefir grains) showed a bactericidal effect on E. coli ATCC 25922 and S. enteric serovar Enteritidis, with a reduction of $99.9 \%$ of the initial counts. The minimal inhibitory value from all the concentrations assayed was $20 \% \mathrm{v} / \mathrm{v}$ for both pathogens. These results suggest that the lyophilization did not affect the antimicrobial activity of kefir.

Effect of CFS on the growth of E. coli ATCC 25922 and S. enterica serovar Enteritidis: E. coli ATCC 25922 showed a relative resistance to inhibition, decreasing only by 1 log cycle during the incubation time with both CFS (Figure 3a). On the other hand, S. enteric serovar Enteritidis was strongly affected by the CFS from fresh and reactivated freeze-dried grains, decreasing 5 log cycles during the incubation time (Figure 3b).
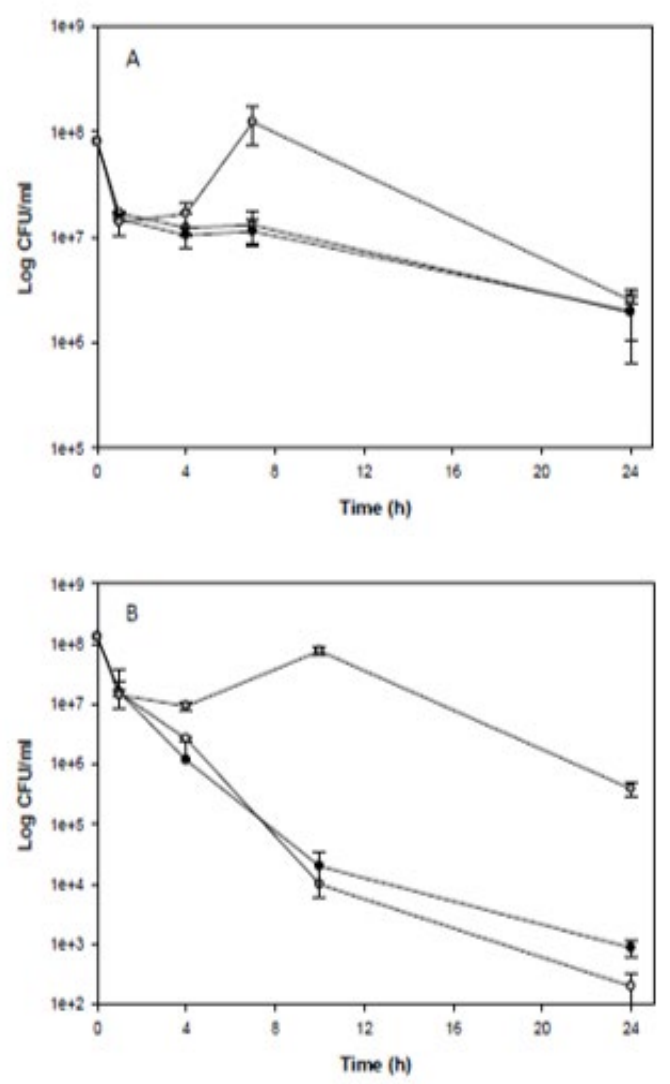

Figure 3. Viability of E. coli ATCC 25922 (A) and S. enterica serovar Enteritidis (B) exposed against Cell Free Supernatants (CFS) obtained from milk fermented with fresh and reactivated freezedried CIDCA AGK1 kefir grains during $24 \mathrm{~h}(\mathrm{O})$ : Microorganisms exposed against CFS from fresh kefir grains; $(\bullet)$. Microorganisms exposed against CFS from reactivated freeze-dried kefir grains.

\section{Sensory analysis of kefir fermented milk with freeze-dried and fresh CIDCA AGK1 kefir grains}

Similarity test: A number 54 triangle sets of kefir beverages obtained with fresh and freeze-dried grains were evaluated. The different samples were discriminated in a total of 23 triangle sets. According to the general answer obtained during the panel ("Which one was the different sample?"), we determined from equation 1, a LS value of $30 \%$. This value was equal to the Pd value, showing that the two samples did not show significant differences in their sensory characteristics. In summary, the panel did not detect differences between kefir obtained with fresh or freeze-dried kefir grains.

Acceptability test: The kefir obtained with freeze-dried grain was evaluated by 93 untrained persons. An average of the ratings assigned by each one was performed and a value of $7.88 \pm 0.35$ was obtained, which correlates with "Like very much".

\section{Discussion}

Previous studies have shown that the kefir grains' biomass increases with successive sub culturing, indicating the viability of the microbial community $[13,23]$. The freeze-dried grains stored at $4^{\circ} \mathrm{C}$ for 6 months exhibited a significant reduction in their biomass increase compared to fresh grains (Figure 1). The reduction of the ability to produce biomass could be attributed to the change in some microorganisms within kefir community such as Lactobacillus kefiranofaciens, which is the main microorganism responsible for the protein matrix production [24-26].

In agreement with these observations, other researchers have showed that the resistance of kefir isolated microorganisms (Saccharomyces cerevisiae CIDCA 8112, K. marxianus CIDCA 8154, Lactobacillus plantarum CIDCA 83114 and L. kefir CIDCA 8348) to lyophilization is a strain-dependent trait [27].

Other researchers have stated that kefir grains stored during 4 months at $4^{\circ} \mathrm{C}$ lose their capability to increase their biomass [13]. According to these results, it is possible that not only the lyophilization but the storage conditions affected the biomass kinetics of the kefir grains. Nevertheless, the use of milk as cryoprotectant could have reduced the microbial injury as it has been previously reported [28-31].

Microbial populations decreased by 3 log cycles during the storage time on the freeze-dried kefir grains that were not activated in milk. In spite of the observed microbial reduction, we could demonstrate that the damage was reversible because the counts reached the same values obtained in the fresh kefir grain once the reactivation step was performed (Table 1). Then, we determined that reactivation of two successive passages on milk was enough to recover the microbial community viability, obtaining similar counts to those of the fresh grains and ensuring the proper acidification of milk.

Previous studies have evaluated the yeast survival from freeze-dried commercial kefir grain and determined that the count decreased by 1 log cycle $\left(10^{3} \mathrm{CFU} \cdot \mathrm{mL}^{-1}\right)$ after the 2 months of storage [11], whereas our results showed an increase in the yeast concentration, showing a count of 1 log cycle over the fresh grains counts during the 6 months of storage. We also assessed the microbial counts of the milk fermented with fresh and freeze-dried grains. Our results showed that the milk fermentation with freeze-dried grains stored at $4^{\circ} \mathrm{C}$ for 6 months, produced a kefir beverage (Table 2) according to the 
conditions required by legislation [22] and the LAB counts were above the yeast counts, as described by Garrote et al. [1].

The acidification kinetics carried out with fresh grains was similar to that obtained by Garrote et al. [4]. Moreover, the acidifications carried out with freeze-dried kefir grains did not show significant differences with that obtained with fresh grains, indicating that the fermentative activity was not significantly affected by the lyophilization and the storage conditions (Figure 2). These results were according with those obtained by Withun et al. [10], who demonstrated that freezedried kefir grains stored up to 10 months preserve the fermentative activity of the grains.

Protein concentrations determined in this work were within the reference values required by the national legislation [22]. Also, these results are in agreement with those reported by Garrote et al. [2], who worked with CIDCA AGK1 fresh grains. On the other hand, titratable acidity of kefir at 3 and 6 months of storage were also within the reference values required by legislation [22].

In this study, we established a MIC value for $S$. enterica serovar Enteritidis and $E$. coli of $20 \% \mathrm{v} / \mathrm{v}$ of CFS obtained from milk fermented with fresh and freeze-dried grains.

Results obtained in this work confirm values determined in previous works that report that MIC values of $30 \%$ from whey fermented with CIDCA AGK10 grains are effective against Salmonella entérica and E. coli $[7,8]$.

Once the MICs were determined, the death kinetics of two pathogens was studied. A bacterial decrease by 5 log cycles and 1 log cycle from S. enterica serovar Enteritidis and E. coli was obtained, respectively, during the incubation time. These results agreed with those reported on the antimicrobial activity of CFS from whey fermented with fresh CIDCA AGK10 kefir grains [7]. It is remarkable that CFS from fresh and freeze-dried kefir grains evidenced the same inhibitory ability. Lyophilization does not affect the inhibitory ability of CFS on the studied pathogens. This is an additional advantage of the lyophilization as a preservation technique for CIDCA AGK1 kefir grains.

The similarity test herein established that there were no detectable differences between fermented beverages with fresh and freeze-dried kefir grains. Additionally, the kefir fermented by CIDCA AGK1 freeze-dried kefir grains obtained a wide acceptability among the surveyed population. These results are also in agreement with those obtained by Kakisu et al. [32], who studied the sensory attributes of beverages fermented with 2 and 3 strains isolated from kefir grains. The fermented milk with the two-strain or three-strain starter was judged as acceptable $(P \leq 0.05)$.

\section{Conclusion}

Lyophilization followed by the appropriate storage conditions is suitable for the survival of the kefir microbiota and the stability of the fermentation activity of the kefir grains. A critical parameter relates with the need to reactivate the freeze-dried kefir grains before their use. Moreover, it was determined that a recovery time is necessary in order to obtain biomass production. The inhibitory activity of CFS against $E$. coli and $S$. enterica serovar Enteritidis is affected by lyophilization but this effect is clearly reverted after the grain reactivation process. On the other hand, there was no significant difference between fermented milk with fresh and freeze-dried kefir grains. Fermented milk with freeze-dried grains shows a very good acceptance.

These results are important for storage of kefir grains during wide periods of time and support their transport without refrigeration. The reactivation process is an important stage to ensure a suitable carriage and therefore maximize their industrial use.

\section{Conflicts of Interest}

There is no conflict of interest with other co-authors for the publication of this manuscript in this journal. All the coauthors have contributed in the preparation of the manuscript up to the submission stage.

\section{Acknowledgement}

We thank to Universidad Nacional de La Plata (UNLP, Argentina) and Agencia Nacional de Promoción Científica y Tecnológica (ANPCyT, Argentina) for financial support. We thank to the staff of Instituto Biológico Dr. Tomás Perón (La Plata, Argentina) and of Centro de Investigaciones y Desarrollo en Fermentaciones Industriales (CINDEFI, Argentina) for technical support.

\section{Author's Contribution}

A.M. carried out all the assays, R.G. performed some experiments and written the manuscript. G.DA, M.D.C.C. and A.L.P. designed and revised the manuscript. All authors agreed with the final version of the manuscript.

\section{References}

1. Garrote GL, Abraham AG, De Antoni GL. Chemical and microbiological characterization of kefir grains. J Dairy Res. 2001; 68(4): 639-652.

2. Garrote GL, Abraham AG, De Antoni GL. Microbial Interactions in Kefir: A Natural Probiotic Drink. In: Mozzi F, Raya R, Vignolo GM (eds). Biotechnology of Lactic Acid Bacteria: Novel Applications. $1^{\text {st }}$ edition. Wiley-Blackwell. 2010: 327-339.

3. Gamba R, Ni Colo C, Correa M, et al. Anti fungal Activity against Aspergillus parasiticus of Supernatants from Whey Permeates Fermented with Kefir Grains. Adv Microbiol. 2015; 5(6): 479-492. doi: 10.4236/aim.2015.56049

4. Garrote GL, Abraham AG, De Antoni GL. Inhibitory Power of Kefir: The Role of Organic Acids. J Food Prot. 2000; 63(3): 364-369.

5. Kakisu EJ, Abraham AG, Perez PF, De Antoni GL. Inhibition of Bacillus cereus in Milk Fermented with Kefir Grains. J Food Prot. 2007; 70(11): 26132616.

6. Londero A, Quinta R, Abraham A, Sereno R, De Antoni G, Garrote Gl. Inhibitory Activity of Cheese Whey Fermented with Kefir Grains. J Food Prot. 2011; 74(1): 94-100.

7. Londero A, Iraporda C, Garrote GL, Abraham AG. Cheese whey fermented with kefir micro-organisms: Antagonism against Salmonella and immunomodulatory capacity. Int J Dairy Technol. 2015; 68(1): 118-126. doi: 10.1111/1471-0307.12161 
8. Ulusoy $B$, Çolak $H$, Hampikyan $H$, Erkan $M$. An in vitro study on the antibacterial effect of kefir against some food-borne pathogens. Türk Mikrobiyol Cem Derg. 2007; 37(2): 103-107.

9. Brialy C, Rivalland P, Coiffard L, De Roeck Holtzhauer Y. Microbiological study of lyophilized dairy kefir. Folia Microbiol (Praha). 1995; 40(2): 198200.

10. Witthuhn RC, Cilliers A, Britz TJ. Evaluation of different preservation techniques on the storage potential of Kefir grains. J Dairy Res. 2005; 72(1): 125-128.

11. Kök Taş T. Effect of storage parameters on freeze-dried kefir grains. Int J Dairy Technol. 2015; 68(3): 434-440. doi: 10.1111/1471-0307.12196

12. Abraham AG, De Antoni GL. Characterization of kefir grains grow in cow's milk and soya milk. J Dairy Res. 1999; 66(2): 327-333.

13. Garrote GL, Abraham AG, De Antoni GL. Preservation of Kefir Grains, a Comparative Study. LWT - Food Science and Technology. 1997; 30(1): 7784. doi: 10.1006/fstl.1996.0135

14. Matissek R, Schnepel F, Steiner G. Food analysis: Fundamentals, methods, applications. Editorial Acribia, S.A. Zaragoza, España. 1998: 430.

15. Vázquez MB, Curia A, Hough G. Sensory descriptive analysis, sensory acceptability and expectation studies on biscuits with reduced added salt and increased fiber. J Sens Stud. 2009; 24(4): 498-511. doi: 10.1111/j.1745-459X.2009.00223.x

16. Lawless HT. Chapter 4: Discrimination testing. In: Lawless HT, Heymann H (eds). Sensory Evaluation of Food, Principles and Practices. $2^{\text {nd }}$ edition. Springer, New York, 2010: 79-100.

17. Lawless HT. Chapter 14: Acceptance testing. In: Lawless HT, Heymann H (eds). Sensory Evaluation of Food, Principles and Practices. $2^{\text {nd }}$ edition. Springer, New York, 2010: 325-347.

18. International Organization for Standardization. Sensory analysis - General guidance for the design of test rooms. ISO 8589. 2007.

19. Johnson DS, Duncan SE, Bianchi LM, Chang HH, Eigel WN, O'Keefe SF. Packaging modifications for protecting flavor of extended-shelf-life milk from light. J Dairy Sci. 2015; 98(4): 2205-2214. doi: 10.3168/jds.2014-8857

20. Hough G. Course: Sensory Food Assessment Workshop. CIDCA, Centro de Investigación en Criotecnología de Alimentos. 9, 10 y 11 de octubre del 2006. Departamento de Evaluación Sensorial de Alimentos. Instituto Superior Experimental de Tecnología Alimentaria. (ISETA) 108.

21. Stone $H$, Bleibaum R, Thomas H. Chapter 7: Affective Testing. In: Stone $H$, Bleibaum R, Thomas $H$ (eds). Sensory Evaluation Practices. $4^{\text {th }}$ edition. Elsevier/Academic Press. 2012: 227-252.
22. Código Alimentario Argentino (CAA). Capítulo VIII: Alimentos Lácteos. In Código Alimentario Argentino. 2006: 553-642.

23. Yokoi H, Watanabe T, Fuji Y, Toba T, Adachi S. Isolation and Characterization of Polysaccharide-Producing Bacteria from Kefir Grains. J Dairy Sci. 1990; 73(7): 1684-1689.

24. Ahmed Z, Wang Y, Anjum N, Ahmad A, Khan ST. Characterization of exo polysaccharide produced by Lactobacillus kefiranofaciens ZW3 isolated from Tibet kefir e Part II. Food Hydrocolloid. 2013; 30(1): 343-350.

25. Fujisawa T, Adachi S, Toba T, Arihara K, Mitsuoka T. Lactobacillus kefiranofaciens sp. nov. isolated from kefir grains. Int I Syst Bacteriol. 1988; 38(1): $12-14$

26. Vancanneyt M, Mengaud J, Cleenwerck I, et al. Reclassification of Lactobacillus kefirgranum Takizawa et al. 1994 as Lactobacillus kefiranofaciens subsp. Kefirgranum subsp. nov. and emended description of L. kefiranofaciens Fujisawa et al. 1988. Int J Syst Evol Microbiol. 2004; 54: 551-556. doi: 10.1099/jijs.0.02912-0

27. Bolla PA, Serradell Mde L, de Urraza PJ, De Antoni GL. Effect of freezedrying on viability and in vitro probiotic properties of a mixture of lactic acid bacteria and yeasts isolated from kefir. J Dairy Res. 2011; 78(1): 15-22. doi: $10.1017 /$ S0022029910000610

28. Abadias $\mathrm{M}$, Benabarre $\mathrm{A}$, Teixidó $\mathrm{N}$, Usall J, Viñas I. Effect of freeze drying and protectants on viability of the biocontrol yeast Candida sake. Int $J$ Food Microbiol. 2001; 65(3): 173-182.

29. Blanquet $S$, Garrait $G$, Beyssac E, et al. Effects of cryoprotectants on the viability and activity of freeze-dried recombinant yeast as novel oral drug delivery systems assessed by an artificial system. Eur J Pharm Biopharm. 2005; 61(1-2): 32-39. doi: 10.1016/j.ejpb.2005.03.009

30. Jofré A, Aymerich T, Garriga M. Impact of different cryoprotectants on the survival of freeze-dried Lactobacillus rhamnosus and Lactobacillus casei/ paracasei during long-term storage. Benef Microbes. 2015; 6(3): 381-386. doi: 10.3920/BM2014.0038

31. Otero $M$, Espeche $M$, Nacer Macías $M$. Optimization of the freezedrying and survival throughout storage of freeze-dried Lactobacillus gasseri and Lactobacillus delbrueckii subsp. delbrueckii for veterinarian probiotic applications. Process Biochem. 2007; 42(10): 1406-1411. 10.1016/j. procbio.2007.07.008

32. Kakisu E, Irigoyen A, Torre P, De Antoni GL, Abraham AG. Physicochemical, microbiological and sensory profiles of fermented milk containing probiotic strains isolated from kefir. J Dairy Res. 2011; 78(4): 456-463. doi: $10.1017 /$ S0022029911000653 